\title{
DIMENSÕES DO MOTOTRABALHO EM PELOTAS-RS: EXPERIÊNCIAS DE (IN)FORMALIDADE E PRECARIEDADE
}

\author{
Dimensions of motorwork in Pelotas - RS: experiences of (in)formality and \\ precariousness
}

João Matheus Soares Miranda'

\begin{abstract}
Resumo
0 propósito deste artigo consiste em debater e compreender sociologicamente o panorama da precariedade e informalidade, que envolve a experiência dos trabalhos de motoboys e mototaxistas na cidade de Pelotas-RS. As reflexões procedem da dissertação de mestrado do autor (MIRANDA, 2017), cujo objetivo fundamentou-se em entender a lógica de inserção e permanência dos mototrabalhadores em atividades consideradas arriscadas e perigosas, bem como analisar a percepção dos trabalhadores sobre os aspectos econômicos da profissão. A ideia aqui apresentada é, partindo dos dados da referida pesquisa, sob metodologia de exercícios etnográficos e história oral, avançar sobre as possíveis análises conceituais de precariedade e informalidade que se configuram na dinâmica do mototrabalho, onde a experiência do emprego socialmente protegido cada vez menos encontra viabilidade e aceitação por parte dos mototrabalhadores. Afinal, o que significa e quais os efeitos do trabalho precário em uma lógica de economia capitalista, na qual a informalidade se apresenta costumeiramente como alternativa disponível ao desemprego e o "formal" exibe traços sintomáticos de precariedade?
\end{abstract}

Palavras-chave: mototrabalhador; (in)formalidade; precariedade.

\begin{abstract}
The purpose of this article consists of discussing and understanding sociologically the overview of precariousness and informality that involves the experience of motoboys and mototaxi riders' work in the city of Pelotas - RS. The reflexions come from the author's Master dissertation, whose objective was to understand the insertion and permanence logic of the motoworkers in activities considered risky and dangerous, as well as to analyze the workers perception about the economic aspects of this job. The idea presented here was based on the data of the research mentioned above, under methodology of ethnographic exercises and oral history. It aims to go forward on the possible conceptual analyzes of precariousness and informality. These concepts are configured in the dynamics of motowork, where the experience of socially protected employment finds less and less viability and acceptance by motoworkers. After all, what does it mean and what are the effects of precarious job on a logic of capitalist economy where informality usually presents itself as an available alternative to unemployment and the "formal" shows symptomatic traits of precariousness?
\end{abstract}

Keywords: motorcycle worker; (in)formality; precariousness.

\footnotetext{
1 Mestre em Sociologia pela Universidade Federal de Pelotas (UFPEL), Pelotas, Brasil. Email:joaomatheusmiranda@hotmail.com.
} 


\section{Cidade e mototrabalho: a inserção na atividade}

Pelotas é uma cidade localizada na região sul do Estado do Rio Grande do Sul, com pouco mais de 344 mil habitantes ${ }^{2}$, de economia pouco diversificada, alicerçada em bases do setor terciário. O passado escravista de exploração nas charqueadas ${ }^{3}$ e a inconsistência do arranjo capitalista industrial das últimas décadas são elementos que ajudam a explicar as fragilidades sociais e econômicas local e, por conseguinte, dão o tom sobre a escassez das alternativas de trabalho e emprego na cidade. Essa é a condição sócio-histórica que deve ser enfrentada pelo trabalhador que busca ingressar no mercado de trabalho pelotense: um mercado formal de trabalho diminuto, instável e profundamente sensivel às crises e oscilações contumazes do capitalismo.

É justamente esse o ponto da discussão que por ora apresentamos. A partir da dissertação de Mestrado (MIRANDA, 2017), sob o título "As experiências dos mototrabalhadores em Pelotas - a esperança vem de moto?", buscamos dialogar com aspectos sociológicos e conceituais de precariedade e os seus desdobramentos em torno do que concebemos como (in)formalidade.

Afinal, o que significa e quais os efeitos do trabalho precário em uma lógica de economia capitalista onde a informalidade se apresenta costumeiramente como alternativa disponivel ao desemprego e o "formal" exibe traços sintomáticos de precariedade? Justamente por ser uma discussão extensa, permeada de contradições e diferentes lógicas de abordagens, sabemos que o tema não se esgotará nas linhas que seguem. Nosso intuito é a partir da empiria da pesquisa realizada e da interlocução teórica-conceitual, avançar e contribuir para o debate que se coloca como um desafio importante no campo das Ciências Sociais.

\footnotetext{
2 Informação disponivel em <https://cidades.ibge.gov.br/brasil/rs/pelotas/panorama>

3 Ver mais em VARGAS, Jonas. De charque, couros e escravos: a concentração de riqueza, terras e mão-de-obra em Pelotas (1850-1890). João Pessoa: Revista de História, jan./jun. 2012.
} 
Inseridos no contexto pelotense, a pesquisa realizada e que orienta nossa discussão entrevistou ${ }^{4}$ onze (11) mototrabalhadores5: Ângelo, Claudinho, Igor, Leandro, Lucas, Luiz, Mirellen, Patrícia, Quevedo, Ricardo e Rodrigo, compreendendo 6 (seis) motoboys e 5 (cinco) mototaxistas. O trabalho de campo foi divido em duas etapas, sendo a etnografia o primeiro método de pesquisa trabalhado e as entrevistas utilizando a metodologia de história oral como segundo momento.

O primeiro grande desafio que pairava sobre o campo da pesquisa dizia respeito às iniciais aproximações e conseguintes dificuldades de entrada nos locais de trabalho, os pontos. A chegada de um estudante pesquisador, vinculado à Universidade, querendo não somente conversar, mas também permanecer por algum tempo nos pontos, causava, além de estranhamento, desconfiança. Levando em conta todo o processo de invisibilidade social que posteriormente reclamariam os mototrabalhadores de serem alvos, é possível compreender o porquê da primeira impressão sentida ter sido a suspeição nas iniciais palavras trocadas. "O que tu quer saber"? - indagavam prontamente os trabalhadores que eram abordados nas entradas dos pontos, logo depois de descobrirem que o indivíduo que se aproximava não era um cliente, mas alguém que queria "saber um pouco deles".

Vale ressaltar que o tratamento dos mototrabalhadores não era permeado por rispidez ou má vontade, mas um comportamento defensivo sob a armadura da descrença. Passado o impacto, marcado pela curiosidade de fazer parte de um "estudo", como diziam, invariavelmente as portas literalmente se abriam para a permanência no local e o desenvolvimento das primeiras observações e conversas mais detalhadas. "Pode sentar, ail!", indicavam, apontando algum sofá desgastado pelos anos de uso ou bancos de madeira igualmente avariados. Ficava claro que, de princípio, embora a presença do pesquisador estivesse autorizada, levaria algum espaço de tempo para que os mototrabalhadores estivessem realmente dispostos a responder algumas perguntas mais elaboradas sobre suas vidas e o trabalho sobre as motocicletas.

\footnotetext{
4 Os nomes dos entrevistados são reais e sua divulgação foi autorizada. Claudinho e Quevedo são, respectivamente, apelido e sobrenome, que preferi manter ao invés do prenome por serem reconhecidos e apresentarem-se dessa forma.

5 Mototrabalhadores podem ser divididos em duas categorias: motoboys (normalmente trabalham com transporte de pequenas cargas e entregas variadas, de documentos a alimentos) e mototaxistas (trabalham com o transporte individual de passageiros).
} 
Agier (2015, p. 34) diz sobre os desafios etnográficos que "fazer pesquisa de campo é estabelecer relações pessoais com quem não conhecemos anteriormente, junto de quem chegamos um pouco na marra“, sendo nossa presença uma espécie de conquista pela "lisura" que demonstramos na relação que se propõe. O atalho encontrado para romper as barreiras da desconfiança e da vergonha demonstrada pelos motoboys e mototaxistas, passava por transmitir uma postura de informalidade no trato e nos diálogos. Permanecer no ponto não poderia significar a quebra ou tolhimento da naturalidade das interações entre os trabalhadores, assim, todo motoboy ou mototaxista que adentrava no recinto era cumprimentado efusivamente na tentativa de se criar ambiente favorável, um recado de tranquilidade face ao receoso estranhamento de quem descobria a novidade: um desconhecido cheio de perguntas e indagações. A "lisura" que destacou Agier, o momento que a confiança se estabelece durante a pesquisa, em nosso caso, se configurou na clara ideia de que o pesquisador que dividia o espaço dos pontos não estava interessado em juízos de valor ou julgamentos de qualquer espécie. $O$ objetivo era saber quem eram os individuos que trabalhavam com as motocicletas, quais as razões de trabalharem nessa atividade, além de conhecer um pouco da história em comum dessas pessoas que ganham a vida em um trabalho estigmatizado e tão penoso.

A possivel retração inicial por parte dos trabalhadores, o medo de falar ou se expor, que de fato aconteceu, era pouco a pouco substituída pelo interesse de mostrarem um pouco do que acreditavam ser a "essência" da atividade. Clifford (2008, p.39), no esforço de ampliar o debate sobre a experiência etnográfica, enunciou que "se muito da escrita etnográfica é produzido no campo, a real elaboração de uma etnografia é feita em outro lugar". Significa que o campo, além de espaço propriamente dito, se constitui como um momento da pesquisa, fator gerador não somente da experiência cultural, mas da formação textual e literária que se produz por conta do observado. Nesse sentido, os momentos compartilhados nos pontos dos mototrabalhadores foram fundamentais no posterior desafio de colocar em palavras aquilo que se destacava nas falas e discursos. Explicando como o trânsito é perigoso, demonstrando as "marcas" deixadas nos corpos pelos 
acidentes sofridos ou até mesmo calculando quanto de dinheiro podem ganhar se trabalharem bastante nos próximos dias, os mototrabalhadores deixavam evidente: queriam falar.

O mototrabalho surge no contexto da cidade e na vida dos indivíduos como uma alternativa à incapacidade de ingresso no mercado tradicional de emprego, via CLT, socialmente protegido pelas garantias jurídicas e previdenciárias. Marcados pela baixa escolarização e/ou formação curricular deficitária, com dificuldades de inserção ou permanência nos postos de trabalhos, atividades precárias e informais se apresentaram nas trajetórias dos entrevistados como meio de ganhar a vida e suprir materialmente de forma mínima e digna seus núcleos familiares. Uma realidade histórica na sociedade do trabalho no Brasil. (POCHMANN, 2006, 2008).

"Meu primeiro emprego foi de motoboy. Pela crise né? Na época não tinha emprego, aí surgiu a feição de motoboy e eu digo, tá vou encarar (ÂNGELO, 2015)." Ângelo (2015) representa e faz parte da porção de indivíduos que encontrou no mototrabalho um caminho frente ao problema do desemprego, no caso do entrevistado, a primeira experiência de trabalho. Rodrigo também iniciou na atividade por dificuldade de inserção no mercado tradicional de emprego, mas com ideia inicial de conseguir outro trabalho de "carteira assinada" tão logo surgisse oportunidade. No entanto, como em outros casos observados, a tendência de permanência no mototrabalho é bastante significativa, por conta da efetiva dificuldade de ingressar em outro trabalho e a possibilidade de fazer render o trabalho economicamente. "Um cara falou: eu vou abrir uma tele-entrega de dia também, tu quer pegar junto? Vou ficando até conseguir um emprego de carteira e não foi aparecendo nada, eu não quis procurar e fui ficando, e eu não quis mais sair" (RODRIGO, 2015).

Diante da infeliz condição do desemprego, a ideia de ganhar a vida trabalhando como motoboy ou mototaxista surge como alternativa viável no horizonte desses sujeitos. Afinal, no imaginário de quem inicia na profissão, apenas uma motocicleta e disposição são necessários para dar início ao labor que dará a chance de algum retorno econômico aos trabalhadores.

\section{Dinâmicas e lógicas de organização do mototrabalho}


Os motoboys e mototaxistas em Pelotas costumam trabalhar por "corrida" (trabalho de entrega) e "viagem" (deslocamentos com passageiros), respectivamente. O elemento "tempo" é, portanto, fundamental para compreender a lógica da profissão, além de um desafio que se colocava no plano metodológico. Como obter a aproximação necessária para o trabalho etnográfico e depois tomar em torno de uma hora do dia com a entrevista, levando em consideração que os trabalhadores estão quase sempre "correndo contra o tempo" e tentando ganhar dinheiro com a otimização da cronologia sobre as motocicletas?

A ideia de realizar entrevistas nos finais de semana não levava em conta a rotina específica da profissão e, consequentemente, a jornada de trabalho que se prolonga aos sábados e domingos. Estes são, aliás, excelentes dias para ganhar mais dinheiro com a demanda dos pedidos delivery em lanchonetes e pizzarias.

Foi fundamental entrar nos espaços de convivio dos mototrabalhadores e poder perceber como o ambiente é organizado e a lógica do seu funcionamento. Através das observações e especialmente com as interações obtidas, conseguimos informações que significaram a real possibilidade de compreender e tentar assimilar a racionalidade aplicada ao mototrabalho.

Dentro dos locais de trabalho dos mototrabalhadores (motoboys e mototaxistas), nos pontos, há uma ordem de saída para realização de uma entrega ou corrida. Nos primeiros exercícios etnográficos ${ }^{6}$ foi percebido que para ter tempo o suficiente para a aplicação da metodologia escolhida, deveria se seguir determinada lógica. Esperar que na fila de saída para o serviço houvesse no mínimo três mototrabalhadores na frente do pretendido entrevistado. Assim, se teria tempo o bastante para concretizar a entrevista sem interrupções. [...] A célebre frase atribuída a Benjamin Franklin parece fazer ainda mais sentido na experiência de trabalho dos mototrabalhadores: "tempo é dinheiro". (MIRANDA 7, 2017)

\footnotetext{
6 Para Geertz, praticar etnografia não é somente estabelecer relações, selecionar informantes transcrever textos, levantar genealogias, mapear campos, manter um diário "o que define é o tipo de esforço intelectual que ele representa: um risco elaborado para uma "descrição densa" (GEERTZ, 1989, p. 15).

7 Os trechos referenciados com o nome do autor são oriundos de anotações dos diários de campo que integraram parte da dissertação de Mestrado que orienta o presente artigo. São descrições que partem dos momentos etnográficos de permanência e interação do pesquisador nos ambientes específicos de convivio dos mototrabalhadores.
} 
Há na descrição narrativa importantes indícios sobre como a dinâmica do mototrabalho, que se impõe aos trabalhadores, molda de princípio a importância do tempo, de não perder tempo. Em uma atividade que é desenvolvida sobre motocicleta, a necessidade da pressa coloca em questão dois apontamentos: os mototrabalhadores precisam de agilidade para ganhar mais dinheiro e isso maximiza potenciais acidentes.

\title{
Os Pontos
}

Ponto é como se chama os espaços ocupados pelos mototrabalhadores enquanto não estão em deslocamento. Em termos de pesquisa e desenvolvimento metodológico do caso concreto, se tornaria o fundamental ambiente para compreensão da lógica profissional e da interação entre os trabalhadores.

Durante a pesquisa, os pontos visitados foram os considerados mais "populares", bem como os mais demandados na região central de Pelotas. Além desses, destacamos outro ponto localizado no Bairro Três Vendas e, ainda, dois motoboys e uma mototaxista que trabalhavam momentaneamente sem vinculação de ponto.

Diante do exposto, vale citar parte do resultado de exercício etnográfico e observação obtidos pelas visitas e permanências nos pontos dos mototrabalhadores:

\begin{abstract}
O ponto normalmente é um local com pouca mobília, sofás ou bancos velhos e sujos, uma mesa e o telefone que receberá as chamadas para os serviços. Pendurado na parede fica um grande chaveiro que recebe a chave de cada motocicleta de acordo com a ordem de chegada. Assim, quando o trabalho a ser realizado é anotado, o motoboy que for o dono da primeira chave sai para o pedido. Quando retorna deixa a sua chave no final do chaveiro e assim o tempo passa, com as trocas sucessivas de chaves e idas e vindas de motos. A ordem de saída só é quebrada quando algum motoboy recebe alguma chamada no seu próprio telefone celular, normalmente algum cliente indicado ou fidelizado. (MIRANDA, 2017).
\end{abstract}

Embora a atividade dispense a centralidade do empregador, há, nos pontos, mínima organização de quem costumeiramente é conhecido como o "dono", normalmente quem aluga em seu nome o espaço. Também é comum que se dedique a analisar a inserção de possiveis novos mototrabalhadores no local, dando preferência a indicações de pessoas "confiáveis", para não 
correr o risco de um mau trabalhador denegrir a imagem que cada ponto tenta construir.

\begin{abstract}
Existe a figura do dono do ponto que controla quem pode ou não trabalhar no local. Ele não exerce o papel de chefe, tampouco é dotado de poderes diretivos sobre o trabalho. O dono simplesmente filtra quem pode trabalhar no seu ponto pela contraprestação da diária e coordena minimamente o local para que funcione sob alguma organização. Os pontos com localização central tendem a ser os mais requisitados e por conta disso atraem os motoboys. O ingresso normalmente é conquistado por indicação, algum amigo, conhecido ou parente que conversa com o dono e aventa a entrada de alguém. Os motoboys pagam uma diária para poderem utilizar as "benesses" do ponto que envolvem a clientela normalmente já estabelecida, sofás surrados e sujos, banheiro, pia e pequenos armários. O valor devido gira em torno de $R \$ 10,00$ (dez reais) e é pago diariamente independentemente se o indivíduo vai trabalhar. É uma forma precária de associação que resguarda a manutenção do local e das contas correntes como aluguel, água e luz. A quantia de cada trabalho realizado fica inteiramente para o motoboy, sendo assim, em uma ou duas "corridas" ele consegue "amortizar" o pagamento destinado ao ponto. O valor cobrado pelo serviço dos motoboys dependerá do local e área da cidade ou da carga transportada. Deslocamentos para regiões mais afastadas tendem a ser mais caros enquanto os trabalhos na região central são sensivelmente mais baratos. Não há uma tabela de preços que garanta o valor, a quantia é acordada no contato e se as partes anuírem faz-se o serviço. (MIRANDA, 2017)
\end{abstract}

Embora a passagem faça referência aos pontos dos motoboys, os locais ocupados pelos mototaxistas expressam as mesmas características, da disposição do mobiliário e espaço ao modelo de organização. Existe, ainda, a possibilidade do mototrabalhador não se vincular a nenhum ponto, trabalhando apenas por seus contatos individuais, o que não é comum por conta da clientela estabelecida pelos pontos tradicionais.

A funcionalidade dos diferentes ambientes de concentração dos mototrabalhadores é a característica comum e marcante, além de ser o local propício para nos inteirarmos a respeito da profissão. Pode parecer contraditório, mas a forma mais adequada que encontramos para conhecer e nos aprofundarmos sobre profissionais do trânsito é no momento em que eles não estão em trânsito. Assim, especialmente nos contatos iniciais com os mototrabalhadores, a possibilidade de entrar nos pontos com a permissão e disponibilidade de quem lá estava, significou não somente a constituição mínima de confiança com o pesquisador, fundamental para quem etnografa e entrevista, mas a efetiva chance de aprofundar a pesquisa e chegar o mais 
próximo possivel do êxito em descobrir como surge o mototrabalho na vida desses indivíduos.

\section{Conceitos de (in) formalidade e o mototrabalho}

O tema da informalidade e especialmente os significados conceituais atribuídos ao termo estão em constante debate entre os que se aventuram nos constantes desafios e dilemas do mundo contemporâneo do trabalho ${ }^{8}$. Keith Hart, antropólogo britânico, é frequentemente lembrado como um precursor estudioso sobre o uso do termo "Informalidade" e os seus desdobramentos nos mercados. Os efeitos da sua pesquisa foram importantes influenciadores para a criação do Programa Mundial de Emprego, criado pela Organização Internacional do Trabalho em 1969 9. Institucionalmente o programa planejava reduzir os problemas da pobreza e desigualdade nos países periféricos do capitalismo. A centralidade do argumento baseava-se na ideia de que economias não desenvolvidas, pouco industrializadas, de baixa escala e competitividade, tendem a formar um importante contingente de indivíduos em idade economicamente ativa à margem de assalariamentos minimamente dignos. (CACCIAMALI, 2000).

A informalidade e a concepção do termo ganham sentido pelo próprio exercício de desvendar o que significa seu avesso, a formalidade, que, no caso brasileiro, é compreendida muitas vezes como o enquadramento às condições de legalidades jurídicas institucionalizadas. Essa é uma possibilidade conceitual que se apresenta e contribui ao debate, mas que encontra limites no próprio dimensionamento do trabalho como valor institucional da sociedade. (GUIMARÃES, 2004)

Cardoso (2013) contribui com uma instigante analogia na tarefa de não somente buscar o conceito da informalidade, mas explicar o seu funcionamento na lógica capitalista vigente. A ideia é baseada na representação do Tesouro Norte - Americano como núcleo de um buraco

\footnotetext{
8 O leitor interessado poderá buscar mais informações em NOGUEIRA, Mauro. "A problemática do dimensionamento da informalidade na economia brasileira", 2016, disponivel em $<$ http:/ / www.ipea.gov.br/portal/index.php?option=com_content\&view=article\&id=28348>

9 Ver em PERES, Tiago. "Informalidade: um conceito em busca de uma teoria". Disponível em: $<$ http:// periodicos.ufpb.br/ojs/index.php/abet/article/view/27956>
} 
negro, o ponto central de uma galáxia, caracterizado como elemento máximo da força de atração. Todas as relações econômicas mundiais vinculam-se, cedo ou tarde, à centralidade do dólar emitido pelos Estados Unidos. Da mais simples troca monetária ao fluxo complexo de renda do maior conglomerado comercial mundial, o buraco negro exerce sua força de atração e se alimenta de tudo que gravita ao seu redor. No entanto, vale lembrar, quanto mais distante do epicentro, mais rarefeito é o poder do buraco negro. No exercício da analogia de Cardoso (2013), a informalidade possivelmente se acomoda nas lacunas esparsas de flutuação ao longe do buraco negro, nas ausências do Estado ou de institutos regulares do Direito, resultando em relações costumeiramente frágeis e precárias, com reflexos sensiveis no plano econômico e social (ausência de seguridade social, dificuldades contratuais, falta de alternativas financeiras e impossibilidades de crédito no mercado, etc.)

O debate conceitual afirmado por Amaral, Druck e Filgueiras (2004, p.227), por sua vez, se orienta por "qualificações e delimitações empíricas precisas", que significa haver uma necessidade relacional fundamental entre o que se propõe teoricamente e o que se apresenta no campo de pesquisa. É uma proposta interessante ao desafio conceitual que se apresenta e oferta ao pesquisador margens para trabalhar com os dados obtidos no campo, por exemplo.

Os mototrabalhadores em Pelotas nos dão interessante oportunidade para buscarmos, no caso concreto, as aplicabilidades e limitações do "informal". O que chama a atenção é a ideia que os trabalhadores compartilham sobre o significado da informalidade na atividade. A divisão se dá entre os que estão respaldados pela legislação ou não. Essa informação é obtida logo nas primeiras conversas com motoboys e mototaxistas, nos ofertando a impressão de que ao afirmarem o seu status logo de início, criam uma imagem de trabalhadores profissionais e confiáveis, dignos de distintiva percepção em relação aos "informais". Essa é uma preocupação que se repete no decorrer dos contatos, especialmente dentro dos pontos de trabalho, a ideia de que estamos diante de espaços em conformidade com a lei e, especialmente, lidando com indivíduos peritos nas atividades da 
motocicleta. A formalidade para os mototrabalhadores se configura essencialmente na condição imposta pelas normas jurídicas e, quando estão inseridos nesse contexto, fazem questão de salientar e deixar claro quem são.

Embora a narrativa da legalidade e a lógica da formalidade se destaquem entre os mototrabalhadores, o início da profissão é normalmente marcado pelo não enquadramento legal no que concerne às exigências dos órgãos de Trânsito e legislação vigente (curso de formação, carteira profissional e emplacamento específico do veículo). Em termos meramente jurídicos, estariam, portanto, inseridos em uma lógica de informalidade. No entanto, há uma movimentação no que diz respeito à "legalização" na medida que a profissão se consolida na vida dos trabalhadores.

Os "clandestinos" surgem nas narrativas dos mototrabalhadores como aqueles que não cumprem ou não trabalham de acordo com a legislação vigente. No caso dos mototaxistas, o "clandestino", além de não estar apto para o exercício de atividade remunerada com motocicleta, normalmente burla a lei usando moto não licenciada para o trabalho, chegando, em alguns casos, ao ponto de pintar a motocicleta na cor laranja, como obriga a lei, para que se torne idêntica à dos mototaxistas "legais". Entre os motoboys, a condição de clandestinidade não é tão forte e abrangente em comparação aos mototaxistas, possivelmente porque as condições impostas para a atividade e regularização da motocicleta sejam menores e de custo relativamente baixo.

O questionamento que se estabelece é: por que não se tornar um mototrabalhador formalizado? Pesa a realidade de que normalmente o indivíduo que inicia no mototrabalho já se encontra em situação econômica desvantajosa. A atividade surge como alternativa diante da ausência de outras oportunidades. O simples fato de ter de comprar a moto para o trabalho já situa o indivíduo em condição deficitária ou de endividamento. Dispender mais dinheiro para a regularização nem sempre é tarefa simples. O curso de capacitação gira em torno de $\mathrm{R} \$ 200,00$ (duzentos reais), no caso dos mototaxistas, além de outras mudanças que devem ser realizadas na motocicleta para que seja identificada como especifica do trabalho. A soma 
do investimento, entre pinturas, itens de segurança, além das taxas de transferência e regularização da moto, pode ultrapassar os $R \$ 1.500,00$ (hum mil e quinhentos reais).

O simples fato de estarem devidamente ajustados com a razoabilidade normativa do Estado, afasta a informalidade como fator presente nas relações do mototrabalho? Ora, embora "legalizados", os mototrabalhadores ainda estão inseridos em uma lógica de distanciamento de proteção social do trabalho na perspectiva regular de emprego e sua atividade, de alto risco em relação aos acidentes e perdas materiais, levando em consideração os perigos do trânsito e a violência urbana, está enquadrada em uma condição razoável de precariedade. É justamente nesse sentido que as noções de informalidade traçadas por Amaral, Druck e Filgueiras (2004), e a proposta de ação empírica se consolidam como alternativa ao caso dos mototrabalhadores em Pelotas. Há um estreitamento conceitual-empírico entre o que os autores designam como informalidade de características nãofordistas e o desempenho das atividades nas motocicletas. Partimos dessa noção de informalidade e suas características para abordar outra questão essencial no debate que se propõe: a precariedade.

\section{Precariedade em pauta: as contradições no mototrabalho}

Os debates conceituais na sociologia do trabalho são pautados, também, pelo exercício de percepção histórica das realidades experimentadas nos diferentes espaços e momentos. Resta, portanto, aos interessados pelos processos contraditórios e complexos da relação entre sociedade e trabalho, o desafio de descortinar os sentidos atribuídos aos conceitos. 10

Será possível dizer que, quando Castel (1998) analisa as metamorfoses do trabalho na França e a resultante precarização das ocupações com a ofensiva neoliberal, há correspondência do sentido de "precarização" com a realidade brasileira? A resposta dessa pergunta pode começar a ser respondida pela própria possibilidade aventada por Castel como alternativa de reestruturação no caso francês: os resquícios do Estado Social. As ideias

\footnotetext{
10 Sobre distintas percepções da "precariedade, " ver: Standing (2013), Alves (2013), Braga (2014).
} 
de um Estado propositor de ações universalistas e republicanas, com finalidade de transformação social, foram historicamente incompletas e, portanto, insuficientes para as condições do caso brasileiro. (GUIMARÃES, 2004, 2009).

Buscamos chamar atenção para o fato de que falar em precariedade significar estar atento sobre que perspectiva se dá ao termo e suas potencialidades teórico-empíricas. No caso brasileiro, parece ser razoável propor noção de que a precariedade no trabalho se configura de forma muito direta a partir do desempenho de atividades instáveis, marcados pela informalidade ou formalização frágil e de condições desfavoráveis sob a perspectiva da proteção social. (ANTUNES, 2006; CARDOSO 2010).

Chegamos em um momento fundamental na análise aqui proposta, pois, é fundamentalmente nesse ponto que o debate conceitual e teórico encontra amplitude, na relação com a empiria. Afinal, por quais motivos classificamos o mototrabalho em um rol de atividades precárias e como os trabalhadores percebem isso em suas vidas?

Podemos começar referindo, desde já, que os dados obtidos a partir dos exercícios etnográficos e das entrevistas demonstram algumas contradições, não dos entrevistados, mas da própria dinâmica do capitalismo que estão envolvidos e inseridos. Os mototrabalhadores em Pelotas trabalham, em sua imensa maioria, sem carteira de trabalho assinada, sendo os mototaxistas, por conta da atividade ser transporte público individual de passageiros e os motoboys por especificidades que podem ser explicados pela lógica do mercado.

Diante da constatação de que nenhum dos entrevistados era detentor de carteira assinada e de que essa era a realidade na categoria, em primeira impressão, acreditamos estar perante um caso típico de precariedade. No entanto, ainda que seja uma realidade, os próprios mototrabalhadores acabaram relativizando essa ideia espontaneamente, com argumentos de racionalidade econômica e de autonomia

Eu não penso em trocar ela por nenhuma outra profissão de carteira assinada. A gente sabe...trabalhar de carteira assinada tu vai ter que cumprir um horário mais fixo, mais rigido, aguentar desaforo de patrão e punhalada de colega "cobra" pelas costas. No nosso emprego, tu fez a tua entrega, recebeu o teu valor...tu vira as costas e vai embora. Num 
trabalho em ambiente fechado tu tem que cumprir o teu horário, o salário fixo e tu acaba não tendo liberdade. Nessa nossa função a gente ganha mais, tu tens uma liberdade maior pra fazer o teu horário, se tu quiser atender tu pode atender, se tu quiser dispensar tu pode dispensar. (LEANDRO, 2016)

A possibilidade de gerir o tempo de forma autônoma, sem subordinação, trabalhando "por conta", encontra respaldo nas narrativas entusiasmadas, embora, como advertimos, essa liberdade de "fazer o próprio tempo e ritmo" significa ser "livre" para trabalhar ainda mais para conseguir cumprir a jornada de trabalhador autônomo.

Pela remuneração, por não ter um patrão assim que fique no teu pé o dia inteiro, né? Tu é livre, tu trabalha na rua, tu não enjoa do ambiente nem das pessoas. Tu tá um pouco aqui, um pouco ali, um pouco lá, então tu é um pássaro livre e por ganhar por produção tá sempre produzindo e tá sempre ganhando mais. Isso aî é minha profissão, só "troco" por um negócio próprio (ÂNGELO, 2015).

Rodrigo (2015) é direto quando explica suas razões para continuar desempenhando o mototrabalho. O salário mínimo, valor de mercado base para trabalhadores sem maiores qualificações, não bastaria para o patamar alcançado com a motocicleta: "o que eu ganhava na moto eu não ganhava em nenhum outro lugar. Eu não vou voltar a trabalhar de carteira e ouvir desaforo de patrão pra ganhar um salário mínimo" (RODRIGO, 2015).

A simbologia da carteira de trabalho como afirmação de segurança nas relações trabalhistas se desfaz nas entrevistas dos mototrabalhadores. A impressão aferida é que o processo de redução de custos que normalmente origina as atividades dos terceirizados e das pessoas jurídicas criadas somente para fins de burlar a legislação, nesse caso específico, proporcionou aumento substancial de renda. Dizem, como nos trechos das entrevistas, que financeiramente é mais vantajoso não ter vinculação de emprego com nenhuma empresa. O paradoxo que se coloca na vida desses indivíduos é que essa diferença de renda só é obtida por conta das longas horas de trabalho sobre a motocicleta, de risco à segurança física e mental. Trabalhar de forma precária e ganhar o que consideram bom dinheiro ou buscar uma inserção socialmente protegida em teoria e ganhar um salário mínimo? É caso atípico onde uma atividade precária, normalmente relacionada à baixa remuneração, indica valores considerados interessantes ao trabalhador. 
Mas o que isso implica no cotidiano do mototrabalho? Jornadas de trabalho extenuantes, longas, de exposição direta às intempéries climáticas e o aumento da probabilidade de assaltos e acidentes. A precariedade, embora relativizada pela melhoria na renda em comparação às experiências profissionais anteriores, volta à tona por conta dos fatores que são indissociáveis do mototrabalho:

\begin{abstract}
Já sofri acidente, vários, mas nenhum grave. Sempre algum tombo alguma coisa assim. O máximo foi um rompimento de um ligamento do joelho. Isso eu considero grave, já uma fratura é um acidente grave, né? Ai sim ai o cara é obrigado a parar mesmo. Agora isso ai (lesão ligamentar no joelho) não fez com que eu parasse. Até hoje eu tenho o rompimento do ligamento cruzado do joelho. Tem que fazer uma cirurgia, eu to esperando na fila do SUS. No inicio era mais tranquilo, hoje tem muito veículo né? Aí o cara é obrigado a andar no zig-zag no corredor, achar qualquer brechinha pra poder entrar porque a moto não pode parar por causa de um carro né? O cliente fica esperando, ai tem outro esperando também, então tu tem que ganhar tempo, não pode ficar parado atrás do carro tu tem que achar uma brecha pra tu seguir em frente (...) Mas é perigoso, né? A minha mãe se preocupa direto tá sempre na minha cola, sempre ligando pra saber se está tudo bem. Cada tombo eu procuro esconder dela, quando me machuco. Eu não moro com ela, mas ela está sempre querendo que eu troque de profissão. Mas eu disse pra ela que não, que isso aí é minha profissão, só saio por um negócio próprio. (...) Mas depois com o tempo tu vais adquirindo experiência e tu vais vendo o que aumenta de risco. É tipo assim, quanto maior a velocidade maior é o risco. Eu procuro não correr, mas a cara dança conforme a música, né? Então quando aumentam as entregas o cara procura andar um pouco mais rápido, então naturalmente tu sabe que tu tá aumentando teu risco (ÂNGELO, 2015).
\end{abstract}

O relato de Ângelo chama atenção aos fatores da precariedade que envolvem a atividade do mototrabalhador. $\mathrm{O}$ fato de precisar correr com a motocicleta para fazer entregas, em menor tempo e em maior quantidade, é o primeiro aspecto de precariedade que se coloca, levando-se em conta o risco. A lesão sofrida no joelho, justamente no desempenho do trabalho, não apenas evidencia o perigo típico da profissão, como permanecer trabalhando machucado por conta da ausência de alternativa faz do exemplo um importante caso para se pensar a precariedade nas diversas possibilidades que o conceito traz.

Claudinho (2017) conta sua experiência, que sob certa medida, guarda relação com a passagem anterior. Nesse caso, o risco do acidente se concretizou na total incapacidade para o trabalho, resultando em praticamente um mês de afastamento, não só pela impossibilidade física 
diante de uma batida, mas por uma sequela emocional. Ainda, na temática das dificuldades enfrentadas no mototrabalho, Claudinho faz referência aos assaltos que, embora nunca tenho sofrido, já vitimou fatalmente um colega de profissão.

Daí outra vez um cara me bateu! Ele até me viu, mas a moto é muito rápida. Me jogou 20 metros. Me arrebentei todo! Não me quebrei mas tive sorte...eu vi a morte ali. A porrada foi muito grande. Fiquei com trauma e fiquei 30 dias parado. Eu tinha um dinheiro, uma economia. [...] Depois, outra vez, eu entrei com um carro na rua e ele abriu, me fechou. [...] Graças a deus eu nunca fui assaltado, mas eu tenho uma concepção minha. Eu tenho medo do transito, não de ser assaltado. Eu vou no bairro perigoso...eu não dou bola pra isso. Se acontecer eu sei como vou lidar com isso.... Um colega meu, apanhou, reagiu e levou coronhada. Foi pro HPS. Um colega meu já morreu em 2004 ou 2005, quis fugir e levou um tiro pelas costas (CLAUDINHO, 2017).

A condição da precariedade se manifesta não somente no risco assumido pela atividade, em seu caráter de saúde e segurança do mototrabalhador, mas nos próprios desdobramentos que a condição de trabalhadores autônomos sem proteção social acarreta.

O risco? Eu não tenho medo de mais nada. Já sofri três assaltos, já me levaram dinheiro e uma moto zero. Não recuperei mais. Prejuizo meu, é o risco que o autônomo tem. Tudo o que acontecer contigo é risco teu. Se te assaltarem, perder a moto, acidente, é risco teu! Tu precisa ter algum reservado pra aquilo ali. (...) É uma profissão super perigosa! Antes eu trabalhava com entrega e agora eu tô no mototáxi. E eu achava a noite perigo, mas eu vejo que o dia é mais perigoso. A noite é mais tranquilo se tu andar bem atento. O problema é que a gente faz muitas entregas em bairros e vilas, e tem muito cachorro, que de dia tu enxerga e de noite não. Daí é queda, e machuca. E agora faz três semanas que eu quase quebrei o braço. Enfaixei mas tive que tirar pra trabalhar. Cortei a tala e fui. Preciso pagar as contas. Se tu parar por três dias tu já sente em casa (...) Enquanto tem saúde tá bom. Eu, por exemplo, sofri o acidente e enfaixei o braço, fiquei 4 dias sem trabalhar...Perdi dinheiro, um bom dinheiro! (RICARDO, 2016).

Embora cada mototrabalhador compartilhe especificidades de suas experiências na atividade, os relatos apresentam similaridades importantes que abordam as formas de precariedade. Acontece uma trama de ações e consequências que se desenrolam em torno da extrema necessidade de fazer valer o tempo para conseguir ganhar mais dinheiro, o que diretamente amplia as chances dos acidentes, situação em que os mototrabalhadores estão constantemente expostos

Todo mundo se acidenta, ninguém escapa. Entre queda e coisinha assim, devo ter tido 8 ou 9. é que no início quando eu comecei eu era mais estabanado. Tu não tem tanta experiência e ai tu acha que se tu sair correndo feito louco tu vai ganhar o triplo do dinheiro. Depois tu vai 
vendo que fazendo isso tu vai ganhar 10, 20 pila numa noite ou num dia pra fazer o que tu faz. Ai tu acaba tirando mais o pé do acelerador ganhando um pouco menos, mas vendo que vale a pena porque tu destrói menos a moto e arrisca menos a tua vida. No início não, no início pegava a moto saia feito louco "dava" com as duas! Era sinaleira... não tinha ruim! Andando a $80 \mathrm{~km}$ a $90 \mathrm{~km}$ no meio do transito (...) O meu primeiro acidente foi uma coisa estranha: eu entrei na rua, eu me lembro de entrar na rua, e depois eu não me lembro de mais nada! Só me lembro de estar atirado no chão procurando meu celular. Deu um apagão, eu não vi nada. Daí eu bati numa parede, a moto bateu na calçada e eu voei e bati com a cabeça na parede. Esse foi culpa minha porque eu cai sozinho. Ai eu tive um acidente que o cara me fechou. Noutra vez foi culpa minha e do outro condutor porque estava chovendo. Eu vinha muito rápido pra um dia de chuva. Ai inexperiente na época, o cara freou o carro na minha frente e eu acabei freando a moto pra não bater e, a moto deslizou. Foi um pouco culpa minha e um pouco culpa dele! Se eu tivesse devagar eu não tinha caído e se eu tivesse experiência eu não tinha tocado o freio. Mas a maioria dos acidentes que eu tive foi culpa de terceiros (...) A minha mulher no início não gostava muito, até hoje ela não gosta de eu trabalhar de noite. Minha mãe não gosta porque ela acha que é muito risco, mas hoje em dia eles aceitaram. No início foi quando eu tive meus primeiros acidentes eles botaram muito contra, que era pra sair porque isso não era vida! E eu dizia que eu não iria sair porque o que eu ganhava na moto eu não ganhava em nenhum outro lugar. E eu não vou voltar a trabalhar de carteira e ouvir desaforo de patrão pra ganhar um salário minimo (RODRIGO, 2015).

Os relatos aqui apresentados servem para tensionarmos como a precariedade do mototrabalho não se configura em uma lógica exclusivamente contratual, do que é formal ou não, embora seja ponto de partida para avançarmos sobre os efeitos conceituais no campo prático. Não tratamos apenas da ausência da carteira de trabalho assinada e a pensada "segurança" advinda desse tipo de relação, mas a manifestação de preferência dos mototrabalhadores em serem autônomos e arcarem com todos os riscos desse tipo de atividade, assumindo com racionalidade os fatores de precariedade que demonstramos aqui. É uma espécie de esgotamento da centralidade celetista, especificamente nesse ramo, por fatores econômicos e de autonomia sobre o trabalho, ainda que, como já referimos, os resultados dessa forma de trabalhar sejam potencialmente danosos à integridade dos motoboys e mototaxistas.

As variações de desfiguração do emprego "tradicional" com formas de vinculação precárias (parceiros, terceirizados, pejotas, (micro)empreendedores sem alternativa, temporários e, já sob os moldes da 
polêmica reforma trabalhista ${ }^{11}$, os intermitentes), acabaram dando margem para o surgimento de uma série de categorias que não somente contribuíram para a heterogeneização dos trabalhadores em atividades e arranjos laborais fragilizados, como colocaram em xeque a concepção do trabalho socialmente protegido, configurado minimamente sob valores de segurança jurídica e econômica. (MONY e DRUCK, 2007; ANTUNES, 2015). Ainda que a flexibilização dos contratos de trabalho no Brasil, sob o argumento de defesa da competitividade nacional, tenha contribuído para a instauração de um novo período de precariedade laboral, servindo como plano de fundo para a da desoneração do capital, as narrativas dos mototrabalhadores abrem discussão para a ideia da constituição de sujeitos que repensam suas atividades laborais para além ordem celetista. (POCHMANN, 2009, 2012)

É um movimento pendular que se coloca na contradição e a racionalização dos discursos dos motoboys e mototaxistas. $\mathrm{Na}$ mesma medida que se constata a precarização das relações formais de trabalho, do labor resignado à sorte do mercado e da economia, os mototrabalhadores se entusiasmam por um conjunto de vantagens que dizem ter comparativamente aos empregos de vínculo tradicional.

\section{Considerações Finais}

Nosso principal objetivo foi a partir da experiência dos mototrabalhadores em Pelotas - RS, contribuir com possiveis análises conceituais de precariedade e informalidade, buscando dialogar diretamente com as narrativas dos trabalhadores e os importantes achados etnográficos; Inseridos em um contexto onde a informalidade se apresenta normal e cotidianamente, o formal se justifica meramente por questões de enquadramento legal e a precariedade marca sensivelmente a história dos trabalhadores das mais variadas formas, podemos dizer que estamos diante de uma experiência onde os conceitos abordados crescem e ganham sentido

\footnotetext{
11 A reforma trabalhista de julho de 2017 instaurou a modalidade de contratação por trabalho intermitente. O efeito prático desse ponto específico da reforma é a possibilidade de um trabalhador ser contratado para cumprimento de atividades sem jornada definida, ficando a disposição do empregador. A permissividade do trabalho intermitente barateia o custo do trabalho ao mesmo tempo em que impõe ao trabalhador a incerteza sobre horários e especialmente rendimentos.
} 
no diálogo essencial entre o desafiador debate conceitual e a complexa trama da concretude do real.

A importância de avançar conceitualmente sobre os temas da informalidade e precariedade ganha fôlego e complexidade na dimensão empírica das Ciências Sociais, um esforço necessário ao desafio de buscar nas experiências do campo explicações para os fenômenos em questão. É dessa forma que o mototrabalho se apresenta como interessante e importante referencial de debate sobre as contradições de uma realidade laboral que se apresenta multifacetada, marcada pela flexibilização dos contratos e regulamentações, distante do emprego socialmente protegido, de insegurança sobre a atividade, especialmente no que tange aos riscos (econômicos e de segurança sobre o trabalho).

O contraponto dos fatores consideráveis como prejudiciais ou preocupantes sobre a ordem típica ideal do trabalho, digno e justo, é encontrado nas próprias narrativas apresentadas. A construção de discursos sobre autonomia do trabalhador por conta própria e as consequentes vantagens da "liberdade" em relação ao emprego formal sofrem impactos importantes dentro das próprias trajetórias dos mototrabalhadores, nas experiências de dificuldades e fragilidades compartilhadas. É justamente nesse ponto que os reflexos dos processos da informalidade se apresentam no contexto da própria precariedade que adjetiva boa porção das relações de trabalho apresentadas. São, informalidade e precariedade, concepções conceituais que tendem a ganhar força e maior significação dentro de uma lógica de enlaçamento entre definição teórica e desdobramento empírico, em um mundo do trabalho instável e desfigurado.

\section{Referências}

AGIER, Michel. Encontros etnográficos: interação, contexto, comparação. Tradução de Bruno César Cavalcanti, Maria Stela Torres B. Lameiras, Yann Hamonic. São Paulo: Editora Unesp; Alagoas: Edufal, 2015.

ALVES, Giovanni. O que é precariado? Publicado em 22/07/2013. Disponivel em: https://blogdaboitempo.com.br/2013/07/22/o-que-e-oprecariado/ Acesso em 14 de fevereiro de 201c. 
ANTUNES, Ricardo. A era da informatização e a época da informalização: riqueza e miséria do trabalho no Brasil. In: ANTUNES, Ricardo. Riqueza e miséria do trabalho no Brasil. São Paulo: Boitempo, 2006.

ANTUNES, Ricardo. Adeus ao trabalho? Ensaio sobre as metamorfoses e a centralidade do mundo do trabalho. Ed. São Paulo: Cortez; Campinas: Unicamp, 2015.

BRAGA, Ruy. A politica do precariado: do populismo à hegemonia lulista. Ed. Boitempo, 2012.

BRASIL. Decreto-Lei n. ${ }^{\circ} 5.452$, de $1^{\circ}$ de maio de 1943. Aprova a Consolidação das Leis do Trabalho.

BRASIL. Lei $\mathrm{n}^{\circ} 12.009$ de 29 de julho de 2009. Regulamenta o exercício das atividades dos profissionais em transporte de passageiros, "mototaxista", em entrega de mercadorias e em serviço comunitário de rua, e "motoboy", com o uso de motocicleta e estabelece regras gerais para a regulação deste serviço.

BRASIL. Lei $\mathrm{n}^{\circ} 13.429$ de 31 de março de 2017. Altera dispositivos da Lei $\mathrm{n}^{\circ}$ 6.019, de 3 de janeiro de 1975, que dispõe sobre o trabalho temporário nas empresas urbanas e dá outras providências; e dispõe sobre as relações de trabalho na empresa de prestação de serviços a terceiros.

CACHIAMALI, Maria Cristina. Globalização e processo de informalidade. Economia e Sociedade, Campinas: 153-174, jun.2000.

CARDOSO, Adalberto Moreira. A construção da Sociedade do Trabalho no Brasil: uma investigação sobre a persistência secular das desigualdades. Rio de Janeiro: Editora FGV, 2010.

CARDOSO, Adalberto Moreira. Ensaios de sociologia do mercado de trabalho brasileiro. Rio de Janeiro: Editora FGV, 2013.

CASTEL, Roberto. As metamorfoses da questão social: uma crônica do salário. Tradução de Iraci D. Poleti. Petrópolis, RJ: Vozes, 1998.

CLIFFORD, James. Sobre a autoridade etnográfica. In: CLIFFORD, James. A experiência etnográfica: antropologia e literatura no século $\mathbf{X X}$. (Org. José Reginaldo Santos Gonçalves), 3ª ed. Rio de Janeiro, Ed. da UFRJ, 2008.

DRUCK, Graça. MONY, Annie. Terceirização: a erosão dos direitos dos trabalhadores na França e no Brasil. In: DRUCK, Graça. FRANCO, Tânia. A perda da razão social do trabalho: terceirização e precarização. São Paulo: Boitempo, 2007.

FILGUEIRAS, Luiz A. M.; DRUCK, Graça; AMARAL, Manoela Falcão. O conceito de informalidade: um exercício de aplicação empírica. Caderno CRH, Salvador, v. 17, n. 41, p. 211-229, maio/ago. 2004 
GUIMARÃES, Nadya Araújo. Caminhos cruzados: estratégias de empresas e trajetórias de trabalhadores - São Paulo: USP, curso de pós-graduação em Sociologia, Ed. 34, 2004.

GUIMARÃES, Nadya Araújo. Trabalho flexivel, empregos precários? Uma comparação Brasil, França, Japão/Nadya Araújo Guimarães, Helena Hirata e Kurumi Sugita, organizadoras - São Paulo: Editora da Universidade de São Paulo, 2009.

POCHMANN, Márcio. Desempr.egados no Brasil. In: ANTUNES, Ricardo. Riqueza e miséria do trabalho no Brasil. São Paulo: Boitempo, 2006.

POCHMANN, Marcio. O emprego no desenvolvimento da nação. São Paulo: Boitempo, 2008.

POCHMANN, Marcio. Classes do trabalho em mutação. Rio de Janeiro: Revan, 2012.

POCHMANN, Marcio. Qual desenvolvimento? Oportunidades e dificuldades do Brasil contemporâneo. São Paulo: Plubisher, 2009.

STANDING, Guy. O precariado - A nova classe perigosa. Ed. Autentica, 2013.

VARGAS, Jonas. De charque, couros e escravos: a concentração de riqueza, terras e mão-de-obra em Pelotas (1850-1890). João Pessoa: Revista de História, jan./jun. 2012. 